\title{
Paisaje fluvial y planificación del territorio. Perspectivas de integración en la Región Metropolitana de Buenos Aires
}

\author{
Fluvial landscape and territory planning. Perspectives of integration in the Metropolitan Region of Buenos Aires
}

Daniela Rotger*

Fecha de recepción: 16 de agosto de 2017

Fecha de aceptación: 04 de noviembre de 2017

\section{Resumen}

El surgimiento del paisaje como concepto asociado a la planificación del territorio en el marco del proceso de globalización, ha derivado en el desarrollo de un amplio abanico de instrumentos y estrategias destinados a valorar e intervenir paisajes cotidianos y degradados, entre ellos los paisajes fluviales. La Región Metropolitana de Buenos Aires (RMBA), donde las cuencas hidrográficas representan un desafío en materia ambiental, es un territorio propicio para analizar la aplicación de herramientas que impulsen, mediante la puesta en valor del paisaje fluvial, la integración del paisaje dentro de los instrumentos de planificación. El presente artículo tiene como objetivo analizar las posibilidades de integración de las políticas de paisaje dentro de los instrumentos de planificación del territorio en la RMBA, sobre la base del análisis de una estrategia de puesta en valor desarrollada para la cuenca del arroyo del Gato, uno de los que integran este sistema. En una primera parte del trabajo se aborda el marco teórico y metodológico en relación con el paisaje fluvial. Posteriormente se desarrolla la fase empírica, que ahonda en la puesta en valor del paisaje en el caso de estudio. Finalmente se reflexiona acerca de las posibilidades de implementar este tipo de estrategias dentro del marco de planificación actual.

Palabras clave: paisaje fluvial, planificación territorial, Región Metropolitana de Buenos Aires.

\begin{abstract}
The emergence of landscape as a concept associated with land planning in the context of the globalization process has resulted in the development of a wide range of tools and strategies aimed at assessing and intervening in everyday and degraded landscapes, including river landscapes. The Metropolitan Region of Buenos Aires (RMBA), where hydrographic basins represent a challenge in environmental matters, is a favorable territory to analyze the application of tools that, through the enhancement of the river landscape, promote the integration of the landscape into the planning. The present article aims to analyze the possibilities of integration of landscape policies within the land planning instruments in the RMBA, based on the analysis of a development strategy developed for del Gato stream, one of the streams that integrate this system. In a first part of the work the theoretical and methodological framework in relation to the fluvial landscape is addressed. Subsequently, the empirical phase is developed, which deepens the value of the landscape in the case study. Finally, we reflect on the possibilities of implementing this type of strategies within the current planning framework.
\end{abstract}

Keywords: fluvial landscape, Metropolitan Region of Buenos Aires, territorial planning.

\footnotetext{
* Filiación: CONICET- Centro de Investigaciones Urbanas y Territoriales, CIUT, Facultad de Arquitectura y Urbanismo, Universidad Nacional de La Plata, Buenos Aires, Argentina. Correo electrónico: rotgerdaniela@hotmail.com
} 


\section{Introducción}

Junto con los temas urbanos propios de fines del siglo XX -entre ellos la expansión urbana, la revalorización de las identidades locales y el aumento de la conciencia ambiental- emerge la noción de "paisaje" dentro de la planificación del territorio como un concepto capaz de incorporar la dimensión ambiental, la mirada patrimonial y el relevamiento de la percepción social dentro de los procesos de planificación. Las explicaciones de esta articulación conceptual y metodológica son indagadas principalmente desde los aportes teóricos de Joan Nogué (2014; Nogué y Sala, 2008), Rafael Mata (2008; Mata; Tarroja, 2006), y Rocío Silva Pérez y Víctor Fernández Salinas (2015), quienes incardinan el surgimiento de esta categoría al incremento de la conciencia ambiental y la preocupación por valorar el patrimonio en un sentido amplio; además de James Corner quien enfatiza en el interés en el paisaje para intervenir en grandes extensiones territoriales (Ábalos, 2009), y José Feria Toribio y Jesús Santiago Ramos (2017), quienes destacan el papel de los espacios verdes como elementos estructuradores del territorio.

En el continente europeo, entre fines del siglo $X X$ y principios del siglo $X X I$, comienzan a surgir estrategias de distinto tipo destinadas a articular paisaje y planificación territorial, las que pueden agruparse en normativas, métodos de diagnóstico y proyectos, basadas en una concepción amplia del paisaje, entendido como un atributo perteneciente a cualquier parte del territorio. Según la definición del convenio europeo del paisaje: "cualquier parte del territorio tal como la percibe la población, cuyo carácter sea el resultado de la acción y la interacción de factores naturales y/o humanos" (Convención Europea del Paisaje, 2000, p. 2).

Dentro de la línea normativa se destaca el mencionado convenio por su importancia como tratado a nivel continental; por su parte, dentro de la línea diagnóstica o valorativa los principales referentes metodológicos relevados son los Atlas de Paisaje de Francia, el instrumento paisajístico Landscape Character Assessment, y los Catálogos de Paisaje de Cataluña, los cuales avanzan en el estudio interdisciplinar y participativo del paisaje; por último, en cuanto a la línea propositiva se destaca el concepto de "parque patrimonial" trabajado desde los autores Joaquín Sabaté
(2004), Pérez Bustamante y Parra Ponce (2004) y Pablo Alonso (2014).

En este marco de valorización de los paisajes cotidianos y degradados, los cursos fluviales comienzan a visibilizarse como áreas de oportunidad para mejorar la calidad ambiental dentro de las ciudades. En este sentido, surgen dentro de las tres líneas descriptas, estrategias de valoración y proyectos específicos para cuencas y cursos dentro del ámbito europeo, que nacen de una concepción evolucionada de los paisajes del agua respecto de las aproximaciones únicamente naturalistas o ingenieriles, y que considera la complejidad del territorio por el que discurren los cursos, según sostiene Ribas Palom (2006).

Entre los métodos de valoración del paisaje fluvial se destacan los aplicados a la cuenca del Río Guadalquivir (Frolova, 2007; Zoido Naranjo, Rodríguez, Ramírez y García Martín, 2011), representando especial interés para el análisis de cuencas con un alto grado de antropización, debido al estudio del paisaje fluvial como hidrosistema, y como territorio apropiado, modificado y percibido por el ser humano. Respecto de la línea propositiva Batlle (2011) identifica los distintos tipos y escalas de intervención entre los proyectos dedicados a intervenir cursos de agua.

Es así como la Región Metropolitana de Buenos Aires (RMBA), donde las cuencas hidrográficas representan uno de los accidentes geográficos más relevantes, y cuya gestión ha significado históricamente un desafío en materia ambiental, por estar asociadas a graves niveles de contaminación e inundaciones urbanas, pero en las que sin embargo persisten valores ambientales $y$ paisajísticos poco reconocidos, corresponde a un territorio propicio para analizar la aplicación de herramientas que asocien planificación territorial y paisaje, contribuyendo a una mayor integralidad en los instrumentos de planificación actuales.

Sobre la base de las iniciativas en materia de valoración e intervención del paisaje desarrolladas dentro del continente europeo se han diseñado herramientas específicas para una de las cuencas más densificadas de la zona sur de la RMBA, la del arroyo del Gato (Rotger, 2017), las que han permitido reconocer valores patrimoniales, ecológicos y paisajísticos, que han 
sido desarrollados mediante el despliegue de un proyecto de paisaje para la cuenca.

El objetivo central de este artículo es analizar las perspectivas de integración del paisaje dentro de la planificación del territorio, en cuencas degradadas de la RMBA, a través del estudio de una estrategia de puesta en valor del paisaje desarrollada para la cuenca del arroyo del Gato, una de las cuencas más pobladas de la zona sur de la región.

La hipótesis que guía el presente trabajo sostiene que los instrumentos y estrategias desarrollados en Europa respecto de la puesta en valor del paisaje fluvial, pueden ser aplicados en las cuencas de la Región Metropolitana de Buenos Aires, tanto desde la valoración como desde el proyecto, representando un primer paso de cara a la necesaria incorporación de la dimensión ambiental y patrimonial dentro de los instrumentos de planificación territorial.

En una primera parte se desarrollan las nociones y conceptos centrales que definen el problema de investigación: la inserción del paisaje dentro de la planificación territorial, tanto desde lo conceptual como desde lo metodológico; el interés en los paisajes fluviales y el desarrollo de normativas, metodologías de valoración y estrategias proyectuales específicas para cursos de agua; y por último, la problemática en torno a la gestión de cuencas hidrográficas en la RMBA.

En la segunda parte se exponen los resultados de la aplicación de la propuesta metodológica para la valoración del paisaje fluvial en la cuenca del arroyo del Gato, la cual sintetiza los principales aportes de los métodos expuestos en este artículo. Asimismo, se exhibe un proyecto de puesta en valor del paisaje en la cuenca, que se ha basado en los resultados del proceso de valoración.

Para finalizar, se reflexiona acerca de las posibilidades de implementar estrategias de puesta en valor del pasaje fluvial dentro del marco de planificación territorial, tanto en los instrumentos existentes como en los que deberían preverse.

Atendiendo al objetivo propuesto se avanza en un trabajo de enfoque cualitativo, en el que en una primera etapa se desarrolla la construcción del marco teórico y metodológico, y posteriormente se desarrolla la fase empírica, exponiendo la construcción y aplicación de la metodología de valoración, y la propuesta de aplicación, que comprende la formulación de aportes conceptuales e instrumentales que contribuyan a la formulación de estrategias de tratamiento integral del caso de estudio. Las técnicas utilizadas han sido, además de la revisión bibliográfica en torno a los temas centrales de la investigación, el relevamiento in situ de la cuenca (incluyendo la toma de fotografías y la realización de entrevistas a habitantes de distintos tramos), el uso de técnicas de fotointerpretación y el análisis de cartografías que aporten datos acerca de las dimensiones de análisis relevadas en el caso de estudio.

\section{La inserción del paisaje dentro de la planificación del territorio}

La territorialización del paisaje, es decir, el reconocimiento de que cada territorio se manifiesta paisajísticamente en una fisonomía singular y en plurales imágenes sociales, hace del paisaje un aspecto importante de la calidad de vida de la población; porque el paisaje es, ante todo, resultado de la relación sensible de la gente con su entorno percibido, cotidiano o visitado (Mata, 2008, p. 255).

Hacia fines del siglo XX, junto con la necesidad de incorporar la dimensión ambiental dentro de los instrumentos de intervención territorial, emerge la mirada del paisaje, desde la exploración de sus aspectos conceptuales y metodológicos como alternativa para la renovación de las prácticas de la planificación del territorio. El paisaje es un concepto capaz de incorporar lo ecológico y lo patrimonial dentro de los instrumentos de acción territorial; asimismo, desde su entendimiento como territorio percibido, permite añadir la percepción de la población a los procesos de planificación.

La ampliación del entendimiento del patrimonio en las últimas décadas es acompañada por una revisión profunda del concepto de paisaje (Silva Pérez y Fernández Salinas, 2015). En este sentido, Mata sostiene que el aumento de la conciencia ambiental y la necesidad de valorar el patrimonio hacen del paisaje un elemento significativo del bienestar social, asociado al marco de vida cotidiano (Mata y Tarroja, 2006). 
Complementariamente, James Corner apunta la emergencia de "una profunda inquietud por el alcance conceptual del paisaje, por su capacidad para teorizar sobre emplazamientos, territorios, ecosistemas, redes e infraestructuras, así como para organizar grandes zonas urbanas" (Ábalos 2009, p. 133). Comienza a existir, entonces, un consenso general acerca del papel central que desempeñan los elementos naturales y los espacios vacantes, como componentes estructurales y estructuradores del territorio, como recursos estratégicos para acciones de planificación orientadas según los principios del desarrollo sostenible (Feria Toribio y Ramos, 2017).

Emerge una profunda reivindicación de lo local, de los paisajes autóctonos amenazados por la expansión urbana, fenómeno que reúne a colectivos nada minoritarios y a personas de distinta procedencia (Nogué 2014). En palabras de Nogué y Sala (2008) “Lenta y discretamente, empieza a hacer mella la idea de que un entorno atractivo, afable y armónico genera una agradable sensación de bienestar que incrementa notablemente la calidad de vida de los ciudadanos" ( $p$. 70).

Esta inquietud por el paisaje en relación con la comprensión de los procesos territoriales y la búsqueda de alternativas de planificación comienza a plasmarse en el contexto del nuevo milenio, así como en el desarrollo de legislaciones, metodologías y proyectos que vinculan la gestión del paisaje con el ordenamiento del territorio.

En el caso de Europa, continente en el que esta postura tiene un vasto desarrollo, la Convención Europea del Paisaje considera que el valor paisajístico no debe ser únicamente una cualidad de las élites, sino un valor democrático (Ojeda Rivera, 2013). Así mismo, según García García (2015) en este continente, a pesar de los distintos encuadres correspondientes a cada país, se ha ido perfilando un enfoque común refrendado por tratados y convenciones que ha evolucionado desde la protección de paisajes singulares a la valoración de todos ellos. Estos instrumentos pueden inscribirse según de tres líneas diferenciadas:

1. Una línea normativa, que da marco jurídico al tratamiento del paisaje. Dentro de ella puede situarse como instrumento innovador el Convenio Europeo del Paisaje (CEP), tratado internacional auspiciado por el Consejo de Europa, que entró en vigor en 2004. Los países firmantes se comprometen a aplicar políticas para a la protección, gestión y ordenación del paisaje, estableciendo procedimientos para la participación pública e integrando el paisaje en las políticas de ordenamiento del territorio.

2. Una línea valorativa, formada por herramientas de diagnóstico que comienzan a profundizar en el estudio del paisaje a escala territorial desde un enfoque cualitativo. Entre ellas se ubican aproximaciones metodológicas que han evolucionado desde estudios diagnósticos de paisaje puramente objetivos, hasta estudios que cada vez le otorgan un papel más relevante a la percepción social. En el ámbito europeo algunas de las metodologías más relevantes se han desarrollado en Francia (Atlas de paisaje), Reino Unido (Landscape Character Assessment) y Cataluña (Catálogos de Paisaje de Cataluña). Estos métodos se enfocan en identificar y caracterizar paisajes, evaluar sus dinámicas y elaborar objetivos de calidad que puedan insertarse dentro de los instrumentos de planificación correspondientes. Analizan los fundamentos naturales y culturales del paisaje (aspectos objetivos), así como su percepción social (aspectos subjetivos). El Convenio Europeo del Paisaje enfatiza en la relevancia que tienen ciudadanos y agentes sociales y económicos en la planificación del paisaje, desde su caracterización (Nogué, 2010).

3. Una línea propositiva, en la que el paisaje se considera un recurso a desarrollar e intervenir. Desde las disciplinas tradicionalmente abocadas a la intervención del paisaje comienzan a buscarse estrategias que permitan abordar la escala de los paisajes metropolitanos, atentas a conservar el patrimonio local y atender las demandas ambientales. Cuestión de vital importancia en los márgenes de las ciudades, en las periferias urbanas y en espacios intersticiales, donde coexisten elementos heterogéneos y de ardua articulación (Serrano Giné, 2015). Entre este tipo de iniciativas emerge la estrategia denominada como "parque patrimonial", concepto que lleva implícita la noción de proyecto y que, como tal, comporta la construcción de una imagen que contribuye a realzar la identidad a un 
territorio y le provee de elementos que ayudan a desarrollarse económicamente (Pérez Bustamante y Parra Ponce, 2004). Según Sabaté, este tipo de iniciativas cohesionan los recursos del paisaje en base a una idea organizadora "de adelantar criterios para la ordenación de un territorio, para la gestión coherente de dichos recursos" (Sabaté, 2004, p. 13). Por último, cabe señalar que existe una tendencia a crear parques patrimoniales a partir de elementos lineales como ríos, canales o caminos históricos; los que facilitan la estructuración del espacio y el relato de una historia (Alonso, 2014).

Ahora bien, en relación con los paisajes fluviales, aunque han sido estudiados desde diferentes disciplinas y enfoques -sobre todo desde la ecología del paisaje, la geografía física y la hidrología- desde que el paisaje es entendido como atributo perteneciente a la totalidad del territorio, han surgido estudios interdisciplinares que integran perspectivas sociales, culturales y perceptivas. Estos enfoques son superadores de la polarización dominante en materia de tratamiento de paisajes fluviales, una posición asociada al control de la naturaleza que se apoya en el tratamiento ingenieril del agua, y otra que reclama la naturalización y el alejamiento de la interferencia humana (Ribas Palom, 2006).

Desde el plano normativo es necesario remarcar que Europa posee un instrumento jurídico a nivel regional para gestionar las cuencas transfronterizas ${ }^{1}$, además de un marco legal completo para garantizar la cooperación internacional. Dentro de él, la Directiva Marco del Agua $\left(D_{M A}{ }^{2}\right)$, aunque no habla específicamente de paisaje, considera una serie de características físicas, químicas, biológicas, morfológicas, que tienen una incidencia fundamental en la composición del paisaje fluvial (Zoido Naranjo et al., 2011).

La necesidad de estudiar los recursos asociados a los cursos fluviales que impone la directiva marco del agua, junto con el desarrollo de metodologías para la

\footnotetext{
${ }^{1}$ Convenio de la Comisión Económica para Europa de las Naciones Unidas sobre la protección y utilización de los cursos de agua transfronterizos y de los lagos internacionales.

2 Directiva 2000/60/Ce del Parlamento Europeo y del Consejo de Europa, por la que se establece un marco comunitario de actuación en el ámbito de la política de aguas.
}

valoración de paisajes cotidianos, deriva en Europa en el desarrollo de métodos de estudio aplicados al paisaje fluvial. Con el inicio de la aplicación de la legislación paisajística en Europa y la puesta en práctica de metodologías de diagnóstico que pudieran reconocer los paisajes en toda su complejidad, comienzan a surgir propuestas interdisciplinarias que integran estos enfoques, provenientes del campo de la geografía humana. Es así como Francia y España son dos de los países que cuentan con un mayor desarrollo en este campo. La escasez del recurso hídrico en el sur de Europa y, por lo tanto, su alta valoración social, como también el desarrollo de metodologías diagnósticas de paisaje que aportan la base metodológica han impulsado estos enfoques.

En Francia, ya a fines del siglo $\mathrm{XX}$, se registran aportes metodológicos para la valoración del paisaje fluvial, donde el "cuadro metodológico de los paisajistas del ordenamiento" (Dupuis-Tate, 1998), ofrece bases concretas desde el ordenamiento territorial y del paisaje para argumentar proyectos sobre riberas. El estudio diagnóstico sitúa cuatro etapas ${ }^{3}$, para luego dar lugar a la concepción del proyecto de paisaje: análisis de la organización espacial del espacio ribereño, la identificación de los valores culturales y patrimoniales, la identificación de la evolución en los usos del suelo (análisis de usos históricos, actuales y potenciales), análisis de la relación sensible del espacio ribereño y el observador (análisis de las percepciones y de las demandas sociales). Asimismo, el trabajo hace hincapié en el estudio del paisaje fluvial en distintas escalas.

En España cabe destacar las propuestas metodológicas desarrolladas para dos de los ríos más importantes del país, el Río Tajo y el Río Guadalquivir. En el caso del primero -el río más largo de la península ibérica- existe una propuesta metodológica basada en la aplicación del Atlas de paisaje de España a la cuenca hidrográfica, realizada de manera cualitativa y semicuantitativa sobre tramos fluviales.

En cuanto al río Guadalquivir, merecen mención dos trabajos. El primero es una propuesta metodológica basada en el método GTP -geosistema, territorio, paisaje- y conceptos específicos de los paisajes del agua (Frolova, 2007). Esta línea metodológica propone el

\footnotetext{
${ }^{3}$ Traducción del autor.
} 
estudio del paisaje del agua a partir de tres enfoques: como subsistema de un complejo hidrosistema de la cuenca vertiente (geosistema), como resultado del largo proceso de apropiación territorial (territorio), y como dimensión sociocultural de la relación entre hombre y agua (paisaje).

El otro estudio acerca de la cuenca del río Guadalquivir avanza más allá de la propuesta metodológica, proponiéndose como objetivo crear un procedimiento para la incorporación del paisaje en los proyectos hidráulicos y de gestión del agua, así como en la puesta en valor de los paisajes fluviales, incorporando las orientaciones de la Directiva marco del Agua y el Convenio Europeo del Paisaje. En este sentido avanza el estudio Los paisajes fluviales en la planificación y gestión del agua: elementos para la consideración del paisaje en la cuenca hidrográfica del Guadalquivir (Zoido Naranjo et al., 2011), representando especial interés para el estudio de cuencas antropizadas, debido a que integra la organización física del espacio fluvial como hidrosistema fluvial -cada paisaje fluvial está relacionado con los demás paisajes del entorno territorial- y la relación sensible entre el paisaje y el usuario, en un paisaje con un grado de antropización alto.

El procedimiento metodológico que se propone integra elementos físico-naturales, históricos y perceptuales, a nivel de cuenca hidrográfica, planteando diferentes escalas de análisis. La identificación y caracterización de los paisajes fluviales se basa en metodologías como las desarrolladas por el Landscape Character Assessment y el Catálogo de paisajes de Cataluña.

De esta forma el análisis de los componentes del paisaje fluviales se organiza en las siguientes etapas:

1. Fundamentos naturales: relieve, clima, hidrología, bioclima, vegetación, hábitat faunístico potencial, suelos.

2. Procesos históricos y fundamentos socioeconómicos: usos del suelo, tipologías de asentamientos, evolución histórica, sistema de explotación vigente, presiones y dinámicas.

3. Estructura visual y escénica del paisaje e hitos paisajísticos: zonas protegidas y elementos de valor patrimonial.
4. Participación ciudadana: consulta pública acerca de las percepciones del paisaje fluvial.

A su vez, el método plantea el abordaje del análisis en las diferentes escalas espaciales que se dan en los paisajes fluviales, teniendo en cuenta los procesos a nivel de cuenca y curso. Como síntesis de este proceso van a surgir áreas y tipos de paisajes, pudiendo establecerse criterios y estrategias adecuadas al carácter de cada unidad.

Desde la línea propositiva, en tanto, los cursos fluviales comienzan a ser revalorizados en su calidad de cuerpos vivos dentro de la ciudad, portadores de valores ecológicos y paisajísticos y también testigos de la historia urbana. Las estrategias centradas en cursos de agua tienen como objetivo evidenciar el recorrido del agua, poniendo en relieve el desarrollo del ciclo hidrológico dentro de las ciudades. En palabras de Batlle (2011): "Recuperar los drenajes del territorio permite hacer visibles al ciudadano los procesos del agua, al tiempo que se diseña un ciclo hidrológico razonable que da lugar a un nuevo ecosistema urbano" (p. 145).

Siguiendo a Batlle (2011), entre los proyectos dedicados a intervenir cursos de agua desde el paisaje pueden identificarse distintas escalas de injerencia: desde la territorial, hasta la mediana y pequeña escala. Así, desde la escala territorial, los proyectos se basan en la idea de recuperar la visibilidad y calidad de los cursos de agua en toda su extensión, desarrollando espacios públicos a lo largo de toda la planicie de inundación o sectores amplios de la cuenca. En el ámbito urbano los proyectos intentan regresar los cursos a un estado más natural, recuperando cauces entubados y diseñando paseos y parques lineales. Las estrategias de pequeña escala ponen en práctica mecanismos que desde la intervención paisajística inciden sobre el ciclo hidrológico a partir de estrategias ecológicas como reservorios, plantas de fitodepuración y modificaciones del drenaje.

El desarrollo a nivel europeo de herramientas destinadas a la valoración e intervención del paisaje fluvial desde un punto de vista integral, considerando la totalidad de las dimensiones que configuran este complejo paisaje, invita a pensar en alternativas de mayor integralidad para las cuencas de la Región Metropolitana de Buenos Aires, un sistema de ríos y 
arroyos con un alto grado de degradación, que ha tenido un tratamiento deficiente a lo largo de la historia.

\section{Problemática ambiental y gestión de cuencas en la RMBA. Una mirada desde el paisaje}

La Región Metropolitana de Buenos Aires (RMBA) es una unidad territorial formada por la Ciudad Autónoma de Buenos Aires, el Gran Buenos Aires y un conjunto de partidos aledaños, que incluyendo al Gran La Plata formado por los partidos de La Plata, Berisso y Ensenada- suma 40 municipios. Según la información del último Censo Nacional de Población y Vivienda, este conglomerado reúne actualmente una población de 14.839.746 habitantes (Observatorio Metropolitano, s/f), poco más del $37 \%$ de la población nacional.

Esta región se sitúa sobre una planicie apenas ondulada, configurada alrededor del Río de La Plata. Se trata de un territorio fundamentalmente condicionado por el río y por cinco grandes cuencas hidrográficas que definen franjas perpendiculares a su costa (Figura 1): de norte a sur se sitúan las cuencas del Río Lujan y Reconquista, la cuenca del Río Matanza-Riachuelo hacia el suroeste, las cuencas de la Ciudad de Buenos Aires (con cursos totalmente entubados) y, por último, la cuenca de la zona sur.

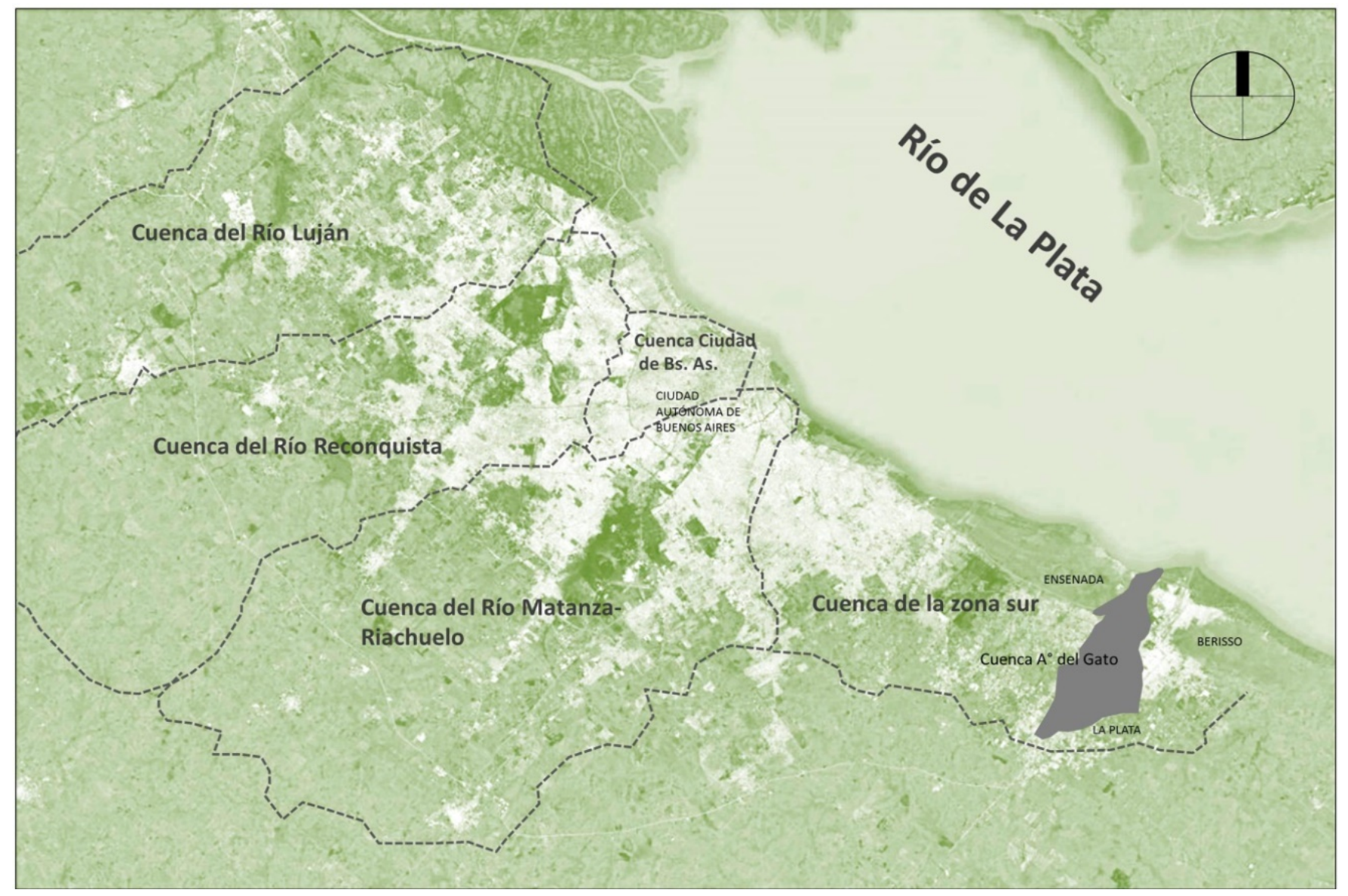

Figura 1. Cuencas de la RMBA.

Fuente: Elaboración propia en base a Imagen de Google Earth, 2017.

El crecimiento de la región ha ido en paralelo al deterioro de las cuencas hidrográficas. Las zonas inundables de ríos y arroyos, los basurales y los rellenos sanitarios, configuran un circuito de contaminación que afecta la calidad de vida de la población y el estado de los espacios verdes (Garay y Fernández, 2013). El Río de La Plata, como receptor de los aportes de estas cuencas, recibe contaminantes de diversas fuentes y tipos: bacterias coliformes fecales, metales pesados $y$ plaguicidas, entre otros (Subsecretaría de urbanismo y 
vivienda, 2007). Asimismo, la problemática de las inundaciones ha acompañado el desarrollo urbano de la región, desde la fundación de su epicentro (la ciudad de Buenos Aires), en la que no existió una adaptación de la cuadrícula española a la topografía local, de modo que las líneas rectas coincidían en oportunidades con los valles de inundación de los cursos de agua. Al iniciarse el siglo XX, y sobre todo a partir de la década del 40, la expansión demográfica y la falta de controles en la urbanización favorecieron la ocupación de los bajos inundables y terrenos no aptos para uso residencial (Nabel y Pereyra, 2000).

La problemática de las inundaciones comienza a cobrar mayor visibilidad con el aumento de la preocupación ambiental, la creciente expansión urbana en áreas frágiles y el incremento de los episodios de precipitaciones de gran magnitud. Como caso extremo puede citarse la inundación ocurrida en la ciudad de La Plata el 2 de abril de 2013, en la que precipitaciones extraordinarias $(392 \mathrm{~mm}$ en 24 horas y $300 \mathrm{~mm}$ en un lapso de cuatro horas), provocaron el colapso de la capacidad de escurrimiento del sistema pluvial y las aguas extendiéndose hacia sus propias planicies de inundación, reocupando las huellas de sus antiguos cauces, produjeron el anegamiento de amplias zonas de la ciudad (Facultad de Ingeniería, UNLP, 2013).

Respecto de la gestión ambiental de la RMBA, la gestión ambiental es dificultosa y se expresa claramente en la falta de gestión integral de las cuencas hidrográficas, debido a la falta de una coordinación interjurisdiccional que supere las divisiones políticas y ordene el territorio desde un criterio y, por lo tanto, una delimitación ambiental, a lo que se suma la dispersión de instrumentos normativos y la falta de instrumentos de planificación de carácter vinculante.

Ahora bien, pese al estado de degradación de las cuencas y las dificultades para incorporar la gestión ambiental, la Región Metropolitana de Buenos Aires posee un gran potencial ecológico y paisajístico que deriva de un sistema de áreas verdes (SAV) (Garay y Fernández, 2013) que los autores clasifican en grandes componentes: "límites" (compuestos por los tres grandes ecosistemas de la región, es decir, el Río de La Plata, el Delta del Paraná y el Área rural); los "elementos" integrados por corredores viales, ferroviarios y fluviales; y la "estructura" que constituyen los límites y elementos y sus relaciones. En esta estructura los ríos y arroyos desempeñan un papel fundamental, al tratarse de conectores que vinculan los grandes espacios verdes, que en su mayor parte están aislados, funcionando además como ejes que articulan las cuencas hidrográficas.

En el próximo apartado se expone una estrategia de puesta en valor del paisaje aplicada en la cuenca del arroyo del Gato, una de las más pobladas de la zona sur de la RMBA, en la que se ha trabajado tomando como referentes las estrategias de valoración e intervención del paisaje desarrolladas en el marco del continente europeo, con el fin de contribuir a la incorporación de la dimensión ambiental y paisajística dentro de los instrumentos de planificación territorial.

\section{Puesta en valor del paisaje en la cuenca del arroyo del Gato. Gran La Plata}

Dentro del Gran La Plata la cuenca del arroyo del Gato (Figura 2) es la más poblada de la microrregión, con una población de 351.713 habitantes y una superficie de 12.400 ha (Facultad de Ingeniería, UNLP, 2013). Se trata de la cuenca con mayor extensión dentro del casco fundacional de la ciudad de La Plata, en el que sus principales afluentes, los arroyos Pérez y Regimiento, se encuentran entubados. El curso principal -el arroyo del Gato- que discurre por el límite noroeste del casco de la ciudad de La Plata, está a cielo abierto prácticamente en su totalidad, recibiendo en su cauce la mayor proporción de desagües pluviales de la ciudad. 


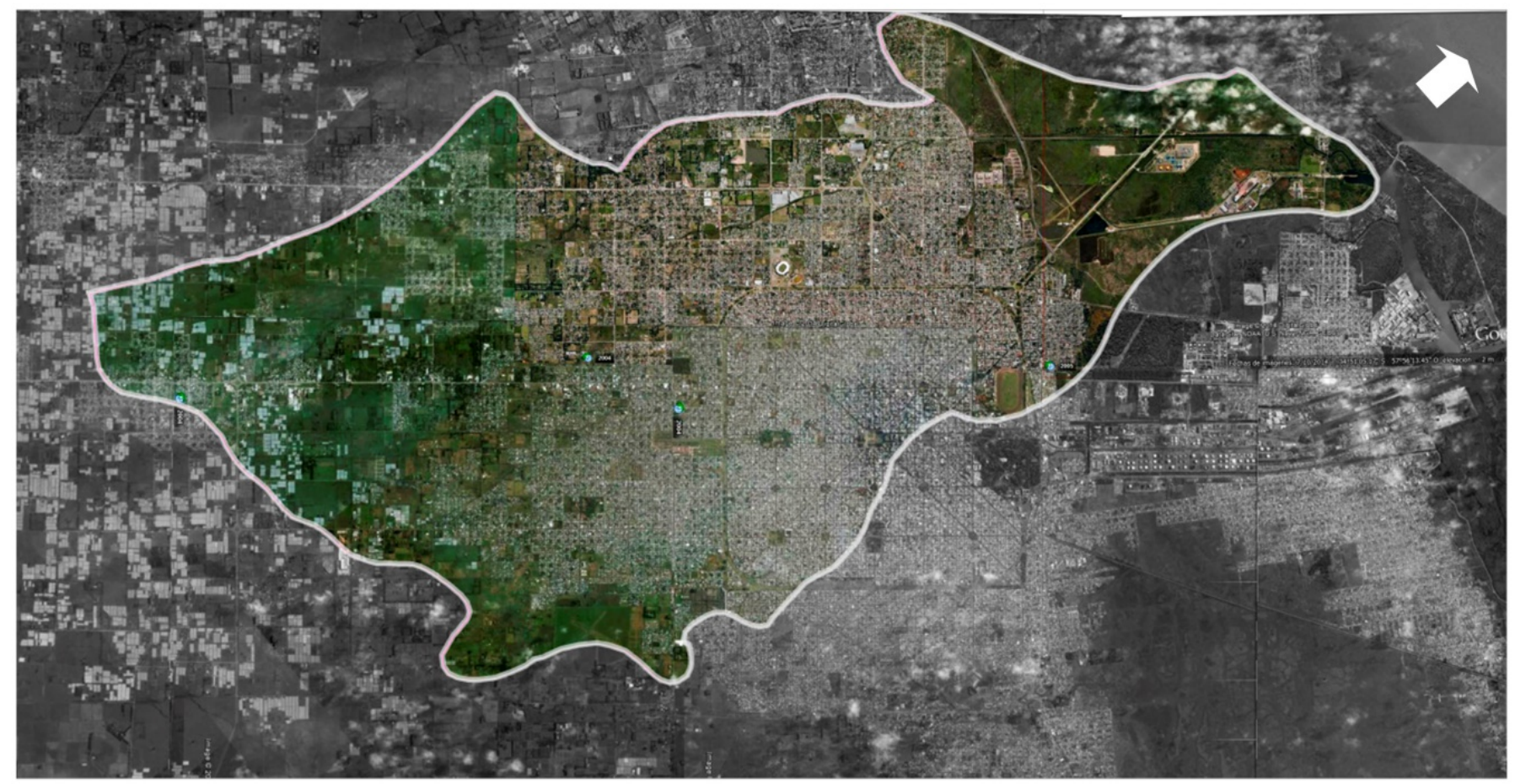

Figura 2. Cuenca del arroyo del Gato.

Fuente: Elaboración propia en base a Google Earth.

Dividiendo a la cuenca en tres tramos -según zona alta, media y baja- pueden detectarse distintos patrones territoriales. En la cuenca alta domina la actividad hortícola intensiva, mientras que en la cuenca media se desarrolla gran diversidad de usos, junto con la mayor densidad poblacional. Además del uso residencial (dentro del que se detecta la ocupación de las márgenes con viviendas precarias), existen actividades industriales, comerciales y canteras a cielo abierto, entre otros. Sobre la cuenca baja el curso del arroyo discurre canalizado por un área de humedales, hasta su desembocadura en el Río Santiago, que se da dentro del ámbito del Monte ribereño, paisaje Protegido de Interés Provincial (Ley $12756)^{4}$.

Su gestión es dificultosa y puede resumirse en algunas de las acciones que el Estado ha desarrollado desde mediados del siglo XX hasta la actualidad, debido a la complejidad territorial de la cuenca, el riesgo hídrico y la contaminación de las aguas, además de la dispersión

\footnotetext{
${ }^{4}$ Paisaje Protegido de Interés Provincial para el desarrollo ecoturístico, a la zona denominada Monte Ribereño Isla Paulino, Isla Santiago.
}

normativa y la falta de una autoridad metropolitana en el tratamiento de las cuencas de la RMBA.

Por ejemplo, el Plan Regulador de 1961 propone un gran sector de la cuenca para radicación industrial, sin tomar en cuenta cuestiones ambientales y paisajísticas. Esta idea comienza a revertirse hacia inicios de la década de 1990, con una mayor conciencia ambiental, además del proceso de retracción de la actividad industrial. Las ordenanzas $9231 / 00$ y $10703 / 10^{5}$-ley vigente- de ordenamiento territorial y usos del suelo para el partido de La Plata, prevén restricciones al uso y ocupación de las zonas inundables de la cuenca.

Durante los años 2012 y 2013 han existido talleres con el fin de trazar los lineamientos para el Plan de Gestión Integral de la cuenca del arroyo del Gato, los que hasta la fecha aún no se ha concretado.

Así mismo, derivadas de la inundación del año 2013, se han desarrollado obras hidráulicas en la cuenca, entre ellas obras de ampliación, canalización y revestimiento

\footnotetext{
${ }^{5}$ Códigos anterior y actual de Ordenamiento Territorial y uso del suelo para el Partido de La Plata.
} 
en hormigón del cauce, derivadores, y relocalización de familias que habitan las márgenes del curso principal.

Las características de la cuenca, tanto por su importancia a nivel regional, como por la carencia y necesidad de políticas integrales de carácter ambiental destinadas a su tratamiento, así como la existencia de su curso principal a cielo abierto en casi la totalidad del recorrido discurriendo por áreas de valor patrimonial y ecológico, la sitúan como un caso de interés para poner a prueba herramientas de valoración y proyecto de paisajes fluviales desarrolladas en Europa.

La estrategia de valoración del paisaje para la cuenca (Rotger, 2017), que se ha aplicado sobre la subcuenca del arroyo del Gato, tomando solo el curso principal que es el que está a cielo abierto, ha considerado el análisis de tres dimensiones de análisis, que resumen los componentes que configuran al paisaje fluvial:

a. Físico-natural: relieve, geomorfología, hidrología superficial y dinámica hidráulica, flora y fauna, calidad del agua, características de las márgenes, morfología del valle y cauce.

b. Histórico-territorial: se analiza en dos fases, en primer lugar, el proceso de configuración territorial, intentando determinar cómo han variado las formas de ocupación y utilización del territorio a lo largo del tiempo; y en segundo término, la configuración territorial actual, en la que se caracterizan los patrones de uso y ocupación del suelo.

c. Simbólico-cultural: se analiza la valoración social del paisaje. Para ello, se ha relevado el patrimonio natural y cultural con reconocimiento legal o institucional, sitios sin reconocimiento valorados por la sociedad, artes plásticas inspiradas en elementos del paisaje y aspectos escénicos y estéticos del paisaje fluvial, valorados desde la observación del curso desde distintas cuencas visuales.

El proceso de caracterización no es solo técnico, sino que cuenta con la participación de la población local, con el objetivo de relevar la percepción de los delegados comunales, vecinos y niños de escuelas primarias acerca del paisaje fluvial.

Sobre la base del análisis de las dimensiones mencionadas y del proceso de participación pública, se han identificado valores del paisaje derivados del medio natural, de la historia urbana de la cuenca, de las potencialidades que ofrecen los patrones actuales de urbanización, valores escénicos, manifestaciones artísticas ligadas al paisaje, y patrimonio cultural con y sin reconocimiento oficial. Estos elementos son usualmente analizados de manera aislada, por lo que valorarlos tomando como unidad de análisis la cuenca es un primer paso de cara a la articulación de recursos a una escala relevante para la comprensión de la dinámica del medio natural en el marco de una región metropolitana.

Algunos de los elementos más relevantes identificados en el análisis del medio natural son: áreas donde el cauce posee poca alteración (las cuales representan aproximadamente un $30 \%$ del largo total del curso principal) y zonas de diversidad de flora y fauna (lagunas, bosques de ribera, humedales y el monte ribereño en la desembocadura). Asimismo, la existencia de márgenes libres en zona urbana y grandes predios vacantes.

Respecto de la dimensión histórica-territorial, puede notarse cómo la ocupación del territorio no ha tomado como una referencia importante al curso del arroyo, ya que se ha desarrollado en franjas paralelas desde el Río de La Plata hacia las tierras más altas. Existen patrones territoriales diferentes que van desde las zonas hortícolas y periurbanas, las que se sitúan en la cuenca alta, pasando por zonas residenciales de ocupación reciente y otras más antiguas, ya consolidadas en la cuenca media, hasta zonas industriales sobre los humedales situados en la cuenca baja.

Desde lo simbólico cultural las únicas expresiones artísticas identificadas directamente en relación con el curso de agua han sido los murales y fotografías surgidos a partir de la inundación de abril de 2013, en tanto que desde los aspectos escénicos y estéticos se han relevado paisajes de interés visual a lo largo del curso, poseedores de valores naturales y culturales, que no cuentan con ningún reconocimiento (Figura 3 ). 


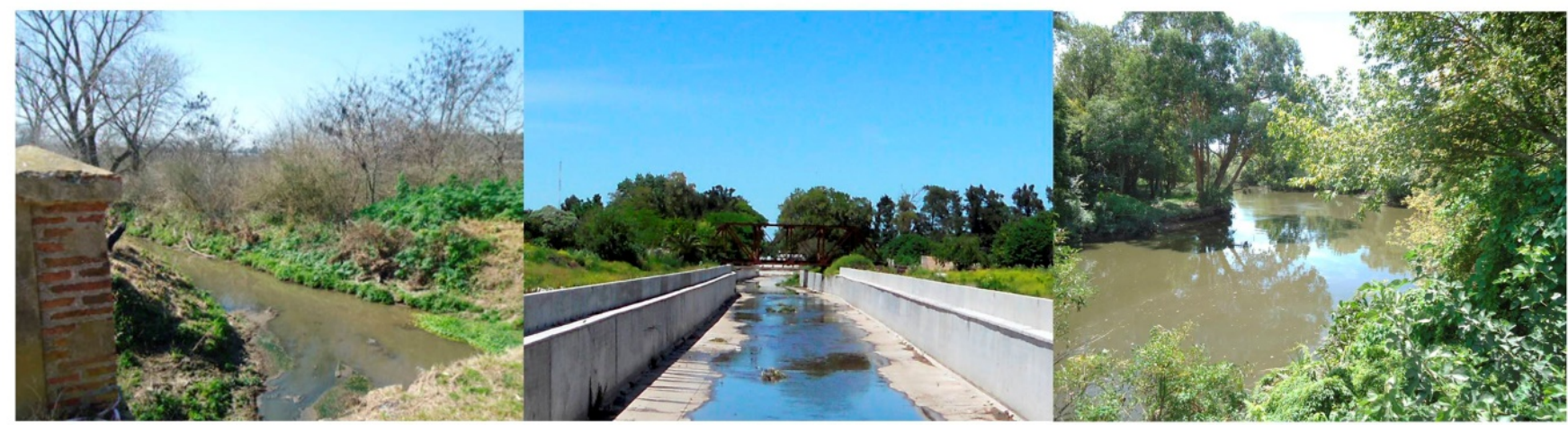

Figura 3. Valores naturales, escénicos y estéticos.

Fuente: Fotos del autor.

Con el objetivo de cualificar la cuenca y, sobre la base de los valores identificados en torno al paisaje fluvial, se han fijado objetivos de calidad para el paisaje $y$ lineamientos de ordenamiento territorial.

Los objetivos planteados apuntan a la protección de los valores culturales y naturales del paisaje, al desarrollo de la cuenca como unidad para su articulación, a asociar el tratamiento del paisaje a la mitigación del riesgo y a crear un espacio público con continuidad a lo largo del curso, teniendo en cuenta las características de cada tramo de la cuenca.

Los lineamientos generales contienen criterios $y$ acciones divididos en tres ejes: curso de agua y recursos hídricos, estructura de movimientos y usos del suelo. Posteriormente, se han trazado lineamientos para cada unidad de paisaje.

Sobre la base de los objetivos y lineamientos planteados se ha avanzado en una estrategia proyectual, cuya finalidad central es consolidar el carácter de la cuenca como elemento organizador de los recursos del paisaje, poniendo en valor los elementos y dinámicas del medio natural. En este sentido, desde las herramientas que ofrece la figura de "parque patrimonial" se ha organizado físicamente la estrategia estructurada a lo largo del curso. Asimismo, se aplican estrategias propias de los paisajes de agua en diferentes escalas, desde el planteo de nuevos espacios públicos asociados al curso, hasta estrategias de menor escala como reservorios y lagunas de fitodepuración.
Algunas de las características principales de la estrategia denominada como parque patrimonial, siguiendo a Pérez Bustamante y Parra Ponce (2004), son el privilegio de las actividades culturales y de esparcimiento en equilibrio con el ambiente, la conservación y el desarrollo del patrimonio natural y construido, la construcción de una imagen que otorga identidad al territorio, el impulso al desarrollo económico a través de la revalorización patrimonial y la particularidad de ser un sitio vivo, donde los habitantes siguen sus actividades cotidianas en un entorno recualificado. Asimismo, en relación con la estructura física de los parques, Sabaté (en Mata y Tarroja, 2006) afirma que los componentes que registran la mayoría de las propuestas se asimilan a los cinco elementos que postula Kevin Lynch en La Imagen de la Ciudad: el ámbito y los subámbitos del parque se asimilan a los barrios; los recursos patrimoniales y servicios pueden compararse con los hitos; las puertas, accesos, centros de interpretación y museos, pueden equipararse con los nodos; así como los caminos se asimilan a las sendas, y los límites visuales a los bordes.

Teniendo en cuenta los elementos que organizan los parques patrimoniales, la estrategia proyectual (Rotger, 2017), tiene como eje de estructuración el curso principal del arroyo y se organiza en tres grandes tipos de paisaje: agrícola, urbano y costero (subámbitos), que son tres franjas a lo largo de la cuenca (ámbito) (Figura 4). 


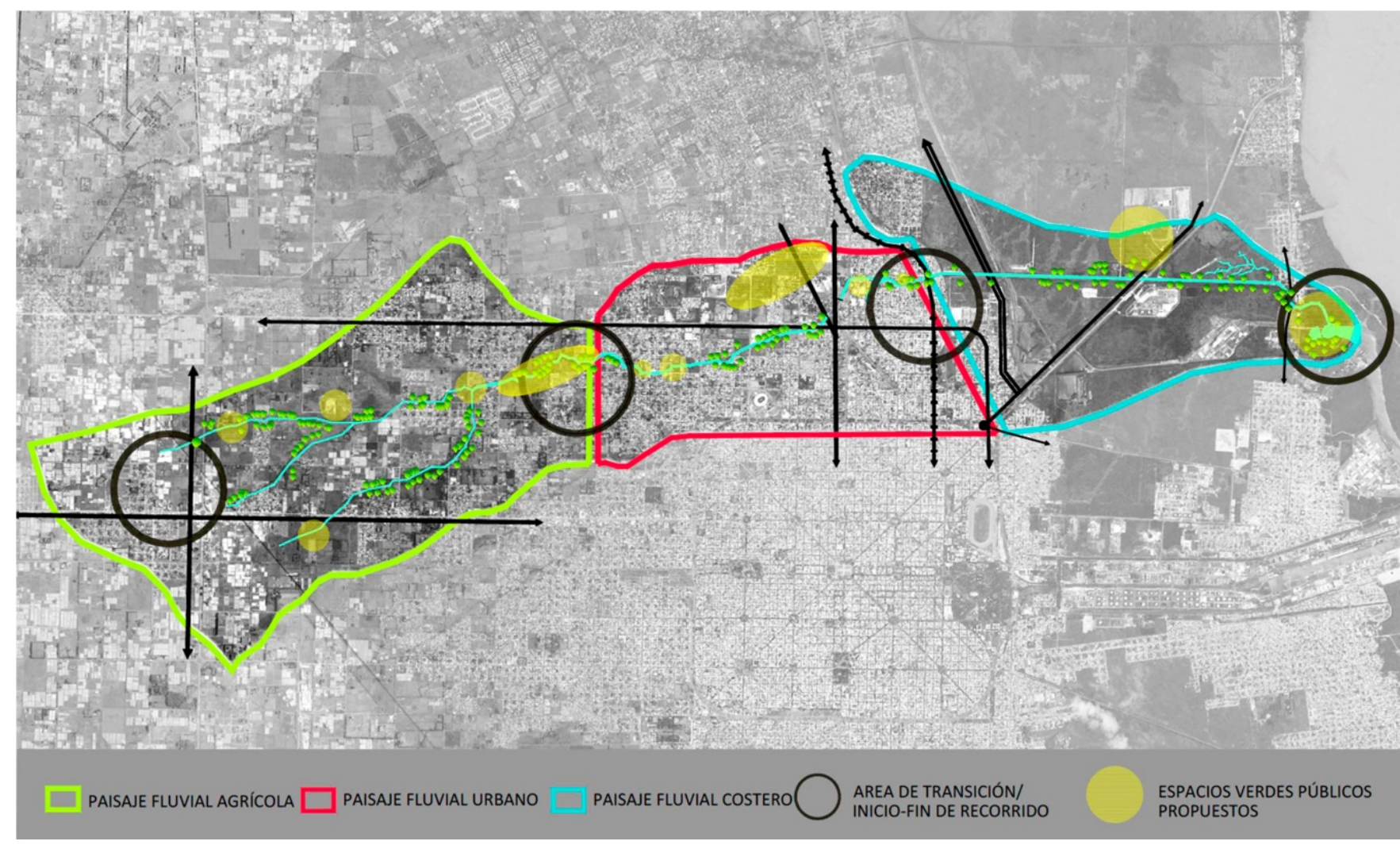

Figura 4. Estrategia proyectual.

Fuente: Elaboración propia.

En el primer subámbito, que es la zona agrícola, correspondiente al sector más alto de la cuenca donde se ubica la naciente del arroyo, se sitúan como principales valores ecológicos y paisajísticos el cauce con escaso grado de modificación, las pequeñas lagunas y los bosques en las márgenes del arroyo. Desde el patrimonio cultural se rescata el valor de la producción florícola y hortícola. En esta zona se propone el desarrollo de actividades educativas $\mathrm{y}$ recreativas en torno a la ecología, aprovechando las buenas condiciones que presenta el curso de agua y los valores naturales del paisaje. Asimismo, se proponen actividades ligadas a la revalorización de la horticultura a cielo abierto, patrimonio cultural fundamental del sector y de la región. Existen tres reservorios para el control de crecidas. Alrededor del primero se desarrolla un parque público con huerta comunitaria, en el segundo un parque con actividades acuáticas, y sobre el tercero, se desarrolla un centro de experimentación vegetal de arroyos y humedales.
En el segundo subámbito, denominado paisaje fluvial urbano, se proponen espacios verdes públicos vinculados con el curso de agua, dado el déficit que hay en la zona, donde además hay espacios vacantes que podrían aprovecharse. El carácter de estos espacios públicos deriva de los valores del paisaje identificados, esencialmente valores escénicos y estéticos y patrimonio cultural. Asimismo, se proponen actividades asociadas a la educación ambiental, la gestión de inundaciones y equipamientos sociales en los espacios públicos.

Por último, en el área de paisaje fluvial costero se plantean actividades recreativas y educativas ligadas a la valorización de los humedales y al paisaje protegido del monte ribereño. Se trabaja sobre todo en estrategias de recuperación y educación ambiental, como fitodepuración, experimentación de energías renovables y reciclaje.

Respecto de los demás elementos que organizan el parque, además del ámbito y los subámbitos, los hitos están representados por los principales elementos 
culturales y naturales del paisaje, y los nodos son los puntos informativos, parques y equipamientos, entre otros. En cuanto a las sendas, se prioriza la continuidad del camino de sirga en todo el recorrido del curso, pasando por caminos más amplios en la zona rural y costera y sendas más estrechas en zona urbana que se adapten a las edificaciones existentes, pero sin perder la servidumbre de paso.

\section{Discusión y conclusiones}

Junto con el surgimiento de la categoría de paisaje dentro del ordenamiento territorial ha emergido el interés por los paisajes cotidianos y degradados, como un modo de mejorar la calidad de vida dentro de las ciudades. En este sentido, los ríos y arroyos comienzan a tener un papel estratégico, por los múltiples beneficios que pueden aportar desde el mejoramiento del paisaje, la recuperación de ecosistemas, la gestión del riesgo hídrico y la creación de espacios verdes públicos. Comienza a ganar terreno, entonces, la idea de que los ríos y arroyos, más allá de la degradación, los problemas sanitarios y su relación con las inundaciones, aportan mayores beneficios a las ciudades, cuando se integran a ellas, en lugar de estar aislados mediante obras de infraestructura hidráulica como entubamientos o canalizaciones.

Mientras la línea normativa del paisaje se abre a la instrumentación de medidas de tratamiento para los paisajes cotidianos y degradados, y en ello de muchos paisajes fluviales; desde la línea valorativa se plantea la necesidad de reconocer los valores paisajísticos de los cursos fluviales de un modo amplio, considerando los aspectos naturales, pero también el proceso de configuración territorial que ha definido la relación ser humana-agua, y las percepciones construidas en torno a este territorio como paisaje.

Desde la línea propositiva, los cursos y sus planicies de inundación, asimismo la cuenca como red hidrográfica, comienzan a vislumbrarse como áreas de oportunidad para el desarrollo de espacios públicos asociados a la revitalización del patrimonio natural y cultural, la gestión del riesgo de inundación y la mejora de la calidad ecológica. En este sentido, el concepto de parque patrimonial, las ideas que lo fundamentan y los criterios para su organización física, resultan adecuados para articular e impulsar los valores del paisaje que se sitúan en la cuenca.

La Región Metropolitana de Buenos Aires es un caso adecuado para estudiar el paisaje fluvial desde las metodologías de valoración provenientes del continente europeo puesto que, debido al deterioro de las cuencas, hay una escasa apreciación y tratamiento de los ríos y arroyos como paisajes fluviales. Asimismo, los aportes de la línea propositiva pueden contribuir al ordenamiento del espacio fluvial: cauce, las márgenes, planicie de inundación, cuenca, permitiendo el desarrollo de procesos ecológicos que podrían mejorar notablemente las condiciones de un entorno urbano de escasa calidad ambiental y paisajística. Asimismo, el diseño de proyectos que tomen la cuenca como unidad y al curso como eje de desarrollo, podrían contribuir a la estructuración y organización del territorio metropolitano.

En el caso del arroyo del Gato, como ejemplo representativo de la situación de las cuencas de la RMBA, la aplicación de una estrategia de valoración del paisaje ha posibilitado la identificación de valores paisajísticos, ecológicos y patrimoniales que no se asocian al imaginario social de la cuenca como espacio degradado. Desde la estrategia propositiva se ha intentado dar respuesta a problemáticas territoriales de la cuenca como riesgo hídrico, contaminación de las aguas o carencia de espacio público- a partir de la puesta en valor de los recursos que ofrece el paisaje.

El paisaje fluvial en la RMBA, como paisaje cotidiano es un desafío para el ordenamiento territorial, debido a su carácter dinámico que "no entra en el concepto de las políticas del patrimonio que se aplican tradicionalmente a los objetos que se creía posible detener en su evolución y "museificar" (Frolova, Toribio y Cancer Pomar, 2003, p. 616).

En el caso de estudio, los resultados del diagnóstico, valores del paisaje, unidades de paisaje, y objetivos de calidad podrían integrarse hoy en los códigos de ordenamiento urbano de cada municipio, y a futuro en los planes de ordenamiento territorial, que hoy no existen en los tres municipios de la microrregión. Asimismo, podrían integrarse dentro de políticas sectoriales relativas al patrimonio, protección de la biodiversidad, espacio público, relocalización 
habitacional; así como dentro de la planificación hidráulica e hidrológica.

Respecto de la estrategia propositiva, el instrumento óptimo para incluir los lineamientos y el proyecto dentro de la planificación territorial sería un plan que comprendiera, por lo menos, a los municipios que integran la cuenca (La Plata y Ensenada), que enmarque el proyecto dentro de un instrumento de gestión interjurisdiccional, pudiendo tomar como unidad la cuenca hidrográfica.

Asimismo, si se concretara el plan integral de gestión de la cuenca del arroyo del Gato, podría incluirse un eje

\section{Referencias}

Ábalos, I. (2009). Naturaleza y artificio. El ideal pintoresco en la arquitectura y el paisajismo contemporáneos. Barcelona: Gustavo Gili.

Alonso González, P. (2014). La transición al posproductivismo: parques patrimoniales, parques culturales y ordenación territorial. Revista EURE, 119(40), 217-238. Recuperado de

http://www.eure.cl/index.php/eure/issue/view/13

Batlle, E. (2011). El jardín de la metrópoli: del paisaje romántico al espacio libre para una ciudad sostenible. Barcelona: Gustavo Gili.

Convención Europea del Paisaje. (2000). Convenio Europeo del Paisaje. Recuperado de http://www.coe.int/

Dupuis-Tate, M. F. (1998). Le paysage fluvial des paysagistes d'aménagement. Revue de Géographie de Lyon, 73(4), 285-292. Recuperado de http://www.persee.fr/

Facultad de Ingeniería, Universidad Nacional de La Plata, UNLP. (2013). Estudio sobre la inundación ocurrida los días 2 y 3 de abril de 2013 en las ciudades de La Plata, Berisso y Ensenada. Recuperado de

http://sedici.unlp.edu.ar/handle/10915/27334 de paisaje donde se desarrollará la tarea de valoración e intervención. Hoy las posibilidades de implementación estarían dadas como proyecto territorial acordado por los municipios de La Plata y Ensenada.

Es decir que, desde la valoración del paisaje fluvial y el desarrollo de una estrategia propositiva, podrían impulsarse las normativas necesarias para proteger las áreas de valor ecológico y los espacios vacantes de la cuenca, así como poner en valor al patrimonio cultural, incluyendo al paisaje fluvial dentro de los instrumentos de planificación territorial en la región.

Feria Toribio J. M. y Ramos J. S. (2017). Naturaleza y ciudad. Perspectivas para la ordenación de la infraestructura verde en los planes territoriales metropolitanos en España. Boletín de la Asociación de Geógrafos Españoles, 74, 117-141.

http://dx.doi.org/10.21138/bage.2447

Frolova, M. (2007). El estudio de los paisajes del agua en una cuenca vertiente: propuesta metodológica. Revista de Estudios Regionales, 83, 21-47. Recuperado de https://dialnet.unirioja.es

Frolova, M., Toribio, J. M., y Cancer Pomar, L. (2003). El paisaje en las políticas públicas de Francia y España: desde la protección del monumento a la gestión del espacio. Estudios geográficos, 64(253), 605-621.

https://doi.org/10.3989/egeogr.2003.i253.200

Garay, D. y Fernández, L. (2013). Biodiversidad urbana. Apuntes para un sistema de áreas verdes en la región metropolitana de Buenos Aires. Los Polvorines: Editorial UNGS.

García García, M. (2015). Perspectivas paisajísticas para la planificación. Revista de Arquitectura de la Universidad CEU San Pablo, 3, 125-139. Recuperado de

https://dialnet.unirioja.es/ejemplar/408003 
Mata, R. (2008). El paisaje, patrimonio y recurso para el desarrollo territorial sostenible. Conocimiento y acción pública. Arbor, 184(729), 155-172. Recuperado de

http://arbor.revistas.csic.es/index.php/arbor/article/ viewArticle/168

Mata, R. y Tarroja, A. (Coords.). (2006). El paisaje y la gestión del territorio. Criterios paisajísticos en la ordenación del territorio y el urbanismo. Barcelona: Editorial de la Diputació Provincial de Barcelona.

Nabel, P. y Pereyra, F. (2000). El paisaje natural bajo las calles de Buenos Aires. Buenos Aires: Ministerio de educación, CONICET, Museo Argentino de Ciencias Naturales Bernardino Rivadavia e Instituto Nacional de Investigación de las Ciencias Naturales.

Nogué, J. (2010). El paisaje en la ordenación del territorio. La experiencia del observatorio del Paisaje de Cataluña. Revista Estudios Geográficos, 269(21), 415-448.

http://dx.doi.org/10.3989/estgeogr.201014

Nogué, J. (2014). Sentido del lugar, paisaje y conflicto. Revista Geopolítica(s), 2(5), 155-163. http://dx.doi.org/10.5209/rev GEOP.2014.v5.n2.488 $\underline{42}$

Nogué, J. y Sala, P. (2008). El paisaje en la ordenación del territorio. Los catálogos de paisaje de Cataluña. Revista Cuadernos Geográficos, 43, 69-98. Recuperado de

http://revistaseug.ugr.es/index.php/cuadgeo/issue/vi $\underline{\mathrm{ew} / 70}$

Observatorio Metropolitano (s/f). Planes y proyectos. Recuperado de http://www.observatorioamba.org/planes-yproyectos/rmba\#datos

Ojeda Rivera J. F. (2013). Lectura transdisciplinar de paisajes cotidianos, hacia una valoración patrimonial. Método de aproximación. Revista INVI, 78(28), 27-75. http://dx.doi.org/10.4067/S071883582013000200002

Pérez Bustamante, L. y Parra Ponce, C. (2004). Paisajes culturales: el parque patrimonial como instrumento de revalorización y revitalización del territorio. Revista THEORÍA, 13, 9-24. Recuperado de http://www.ubiobio.cl/theoria/v/v13/1.pdf
Ribas Palom, A. (2006). Los paisajes del agua como paisajes culturales. Conceptos, métodos y experiencias prácticas para su interpretación y valorización. Versión adaptada de la ponencia "Naturaleza y cultura en la creación y valorización de los paisajes del agua". VII Coloquio Ibérico sobre Planificación y Gestión del Agua. Faro. Portugal. Recuperado de http://web2.udg.edu/aigua/material/apogeo.pdf

Rotger, D. V. (2017). Paisaje fluvial en la región metropolitana de Buenos Aires. Valoración e intervención en la cuenca del arroyo del Gato, Gran La Plata (Tesis inédita para optar por el título de Doctora en Arquitectura y Urbanismo). Universidad Nacional de la Plata, Facultad de Arquitectura y Urbanismo.

Sabaté, J. (2004). El patrimonio como recurso básico para un nuevo modelo de desarrollo. Revista Urban, 9, 8-

29. Recuperado de https://dialnet.unirioja.es/

Serrano Giné, P. D. (2015). Valoración escénica de paisaje periurbano con utilidad en planeamiento territorial. Estudio de caso en la Región Metropolitana de Barcelona. Revista Investigaciones Geográficas, Boletín del Instituto de Geografía, UNAM, 88, 109121. http://dx.doi.org/10.14350/rig.45090

Silva Pérez, R. y Fernández Salinas, V. (2015). Los paisajes culturales de Unesco desde la perspectiva de América Latina y el Caribe. Conceptualizaciones, situaciones y potencialidades. Revista INVI, 85(30), 181-212.

http://dx.doi.org/10.4067/S071883582015000300006

Subsecretaría de Urbanismo y Vivienda - Dirección Provincial de Ordenamiento Urbano y Territorial, SSUyV-DPOUT. (2007). Lineamientos Estratégicos para la Región Metropolitana de Buenos Aires. Buenos Aires: Ministerio de Obras Públicas de la Provincia de Buenos Aires.

Zoido Naranjo, F., Rodríguez Rodríguez, J., Ramírez Ramírez, A., y García Martín, M. (2011). Los paisajes fluviales en la planificación y gestión del agua. Sevilla: Confederación Hidrográfica del Guadalquivir; Centro de Estudios Paisaje y Territorio. Recuperado de http://paisajeyterritorio.es/assets/los-paisajesfluviales-de-la-cuenca-del-guadalquivir.pdf 